\title{
Using the Learners World to Construct and Think in a System of Mathematical Symbols
}

\author{
Judit Kerekes, (Email: Kerekes@mail.csi.cuny.edu ) \\ College of Staten Island, City University of New York
}

\begin{abstract}
The pedagogical implications of the Freudenthal method for the training of mathematics teachers show how adult teachers change their own attitudes and achieve greater student involvement and results.
\end{abstract}

"The best you can do is communicate the spirit of mathematics" - Paul Halmos

\section{Introduction}

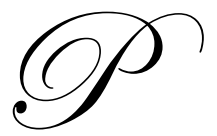

aul Halmos' above admonition (quoted in Albers, 2004, p. 2), that mathematics teachers try to communicate the spirit of mathematics embraces the fundamental recognition that mathematics, its appreciation and understanding, unfolds at the personal level. The distinguished Dutch mathematician and educator, Hans Freudenthal, asserted this profound truth. According to Freudenthal, mathematics is a human activity that unfolds in a process and can be best learned through personal experience (Gravemeijer \& Treffers, 2000). Such experience involves the solving of real life problems; they require mathematization based on reality. Students should therefore be given the opportunity to solve real life problems cooperatively in the classroom. They should be encouraged to appreciate mathematization, and share their findings during whole class discussions. For teacher candidates to appreciate this and transfer such an approach into their own classrooms, the teacher training process itself should employ such a method of instruction, both at the undergraduate and at the graduate level. By going through the same experience, teacher candidates can better appreciate what they are being asked to do after graduation. This is necessary, because as Freudenthal observed, many teachers teach mathematics "as a set of rules of processing or...algorithms" because "it is the way they learned it themselves” (Freudenthal, 1991, p. 3).

Teacher candidates who buy into the Freudenthal approach because they themselves have had personal experience with it during their own training will eventually develop practices that will help their students become young mathematicians in a real and effective sense. That is, their students will be able to think, elaborate, and solve most real life problems on their own. Teacher candidates trained with an understanding and appreciation of the Freudenthal approach, and their students, will be able to successfully change their attitude toward mathematics from the widespread "I hate math" syndrome to the more rewarding and fulfilling "I love math" condition.

The above learning style requires a special environment, and demands math teachers who are well prepared in every respect: subject matter, child psychology, and didactics as a true and scientific analysis and interpretation of the dynamics of teaching and learning. Clearly, such capabilities require intense training, dedication, and a steep learning curve for teacher candidates. However, the burden is 
reduced by the practical nature of the approach, the cooperative and mutually enforcing environment, and the right to learn from mistakes that such an environment automatically fosters. It was with such considerations and expectations in mind that the author decided to engage her students in such an experience, the reporting and analysis of which is the subject of this article.

\section{Some Background: Freudenthal and Realistic Mathematics Education}

Hans Freudenthal, Dutch mathematician and mathematics educator is undoubtedly a pivotal figure in the history of mathematics education. Perhaps the insights and revolutionary approaches he brought to mathematics education emanated from his original training as a mathematician. For Freudenthal was first and foremost a distinguished mathematician, who in his attempts to find efficient ways to teach mathematics, developed an approach and principles that successfully challenged the thinking of his times. As Gravemeijer and Terwel (2000, p. 777) put it: "Hans Freudenthal's views contradicted almost every contemporary approach to educational 'reform'... his ideas, which may at times have seemed to embody recalcitrance for its own sake have now become widely accepted". Those same authors concluded that the revolutionary thinker's effect was "not only in mathematics education, but also in the development of curriculum theory and research methodology" (p. 777).

Freudenthal was chair of mathematics at Utrecht University for almost three decades, and founder of the Institute for the Development of Mathematical Education in Utrecht, Holland (O'Connor \& Robertson, 2000). Questioning the mechanistic approach of the mathematical trends of the 1960s, Freudenthal would turn to an activity-based model of mathematical education that he called reality based. This approach to mathematics education, named Realistic Mathematics Education (RME) involved a theory of learning and teaching mathematics "based on the concept of mathematics as a human activity" (Streefland, 1991, p. 15).

The effect of Freudenthal on mathematics education in the Netherlands between 1980 and 1990, a span of only a decade, was at the very least beyond dramatic. In the 1980, ninety-five percent of all textbooks for mathematics in primary schools followed the mechanistic approach, with only $5 \%$ adapting does the author mean adopting here? It would seem to make more sense. the realistic approach. In 1990, 25\% remained mechanistic while $75 \%$ of the textbooks were realistic (Treffers 1991, p. 11).

RME is about how students learn mathematics, and how mathematics should be taught. It insists that students should not be passive recipients of ready-made mathematics, and mathematics should not be presented as an abstraction totally removed from the everyday experiences of the learner. Consequently, students should be taught/encouraged to create their own systems or internalize the process of such creations; because it is by doing that, they learn best. They should reinvent mathematics by doing it, by mathematizing the real world through analysis, organization, synthesizing, and construction of situations based on their level of understanding (van den Heuvel-Panhuizen, 1996). Freudenthal believed "a fundamental change in teaching attitudes" was necessary before such an approach could gain ground (Freudenthal 1991, p. 30).

At the core of that, change was the process of mathematizing. Freudenthal saw two distinct forms of mathematization: horizontal and vertical mathematization (Freudenthal, 1991, pp. 41-42). Horizontal mathematization involved set patterns, rules, and models that needed to be learned by learners and applied in abstraction, in accordance with set principles. Vertical mathematization required real life experience and flexibility in the course of application, and allowed students to shape, reshape, and manipulate comprehendingly, and be able to reflect upon and adjust their results when necessary. The first could 
only be applied if the student remembered what had been memorized. The second was a living experience that could be summoned and applied at any time. Freudenthal concluded that such a vertical approach to mathematics education could not be designed outside classrooms. He wrote: "Innovation in education is a great learning process on the part of society, which cannot be programmed in advance. As I see it, it starts in the classroom, in a rapid cycle of design, tryout, evaluation, and adaptation" (Freudenthal, 1978, p. 33).

The teachings of Freudenthal influenced Catherine Fosnot and Maarten Dolk, who attempted applications of the Dutch mathematician's realistic approach in the United States. Their Mathematics in the City project for in-service teachers in New York City, in which this author participated, represented a major adaptation of the Freudenthal approach in New York City early childhood and elementary education. It was also a significant introduction of Freudenthal into mathematics education in the Unites States.

\section{American Adaptations: Catherine Fosnot, Maarten Dolk, and the Freudenthal Method}

In the beginning paragraphs to their Young Mathematicians at Work volumes, Fosnot and Dolk (2001) outlined the problem that inspired them to seek new directions in mathematics education:

It is a truism that the purpose of teaching is to help students learn. Yet in the past teaching and learning were most often seen as two separate, even polar, processes. Teaching was what teachers did. They were supposed to know their subject matter and be able to explain it well. Students were supposed to do the learning. They were expected to work hard, practice, and listen to understand. If they did not learn, it was their fault; they had a learning disability, they needed remediation, they were preoccupied, they were lazy. Even when we spoke of development, it was usually to assess learners to see whether they were developmentally ready for the teacher's instruction. (p. 1)

Such an approach fit perfectly into the traditional and mechanistic approach to mathematics education and preserved the total abstractization and fear of mathematics that prevailed in many classrooms. Fosnot and Dolk attempted to erase the feeling of fear and lack of personal engagement in mathematics learning and teaching, and to replace that with learning and teaching environment that encouraged mathematization and made mathematics an experiential learning opportunity, open to all levels and learners' pace. They attempted to evoke the teachings and desired practices of the Freudenthal Method.

Mathematics in the City brought together two mathematics educators. Fosnot, a professor of education at the City University of New York is a constructivist who described the constructivist view of learning as suggesting "an approach to teaching that gives learners the opportunity for concrete, contextually meaningful experience through which they can search for patterns, raise their own questions, and construct their own models, concepts, and strategies” (Fosnot, 1996, p. ix). Dolk, a researcher at the Freudenthal Institute in the Netherlands, developed in-service materials for mathematics teachers.

Fosnot and Dolk were a step ahead of their time. Almost four years after the start of their project, the National Council of Teachers of Mathematics (2000) began encouraging teachers to make the shift from transmitters of knowledge to developers of free, collaborative, context-rich learning environment, where their role as facilitator would be help students construct their own growing knowledge. Such an admonition required teachers to develop working theories and practices that facilitated preparation of 
learners operating in real situations, and with the time and possibility to adapt, adjust and progress at their own pace.

The architects of Mathematics in the City also understood that teachers' framework of teaching derived from their beliefs about the teaching-learning process. If teachers could be encouraged to make decisions based on their students' development, design activities, pose questions, and interact with students to help to learn, then they could facilitate the growth of creative, mathematically thinking students, who recognize relationships, communicate, and prove those relationships. For in a real classroom each child is in a different place developmentally. To elevate students gradually and to introduce those to new and gradated challenges should become the goal of the teacher (Treffers, 1987; Kerekes \& Fosnot, 1998).

\section{The Experience: Hypothesis and Social Context}

The hypothesis governing the practice reported here emanates from the Freudenthal approach and is further informed by the work of Fosnot and Dolk. That hypothesis asserts that personalized mathematization that employs real life problems and solutions and permits students greater flexibility as well as varying levels of difficulty in their progression from less to more mathematical efficiency can develop desirable mathematical attitudes and facilitate greater learning and teaching of mathematics. Tall (1994), examining the difficulties faced by students in the study of mathematics, concluded:

If they are given opportunities to develop mathematical thinking processes, albeit with initially easier mathematics, they develop attitudes to mathematics more in line with those preferred by mathematicians while standard mathematics lectures designed to "get through the material" may force them into the very kind of rote-learning that mathematicians abhor. (p. 1)

Tall acknowledged that students had problems with learning mathematics, and as a mathematics teacher himself, saw the need for a better way. He understood a math educator's mission, which is to pass on to students, the future generation of a constantly changing and advancing society, the knowledge, and love of mathematics. To do so successfully, teachers could be better served if they avoided mechanically teaching the required abstract material from textbooks, according to predetermined steps and procedures, and instead created and nourished learning environments in which children from their pre-K years through college would have a strong desire to think and learn.

Such an empowering environment will have a place and space where the child feels good, because each day brings new challenges appropriate to the child's level and capable of engaging his/her attention. The experience is enhanced by sensitive guidance of a teacher who leads the child through his/her own learning trajectory and does so with love and understanding, because he/she is capable of following the child's thinking and logical process. Consequently, not only does the child's thinking ability develop, but his/her common/practical sense does so as well. Because day by day the student is faced with real life problems, which he/she learns to solve on his/her own, in an interdisciplinary environment, the child learns how to think independently, communicate his/her thoughts and ideas in a logical manner, and is able to follow and understand others. The ability to pay attention to and understand others translates into an added ability to reach consensus with others, one on one, or in small groups. A child who is the beneficiary of such an experience will also be able to present to the whole class his/her own individual findings as well as the collective findings of his/her work group. Paraphrasing the ideas or thoughts of others becomes easier. Students thus trained can evolve into mathematical thinkers; they can truly become young mathematicians. 
This quest to personalize mathematics and make it more appealing to students is necessary because mathematics, though predominantly abstract in its constructions, is designed to provide a structured basis for the enunciation of scientific explications of practical significance. In that sense, mathematics, like all scientific pursuits, cannot be removed from everyday life and hope to be of use. Mathematicians therefore strive to make mathematics an integral part of everyday existence. It is in that context that mathematization becomes essential, for mathematization requires individual involvement; it requires personal experience. This personal experience or personalization of the mathematical problem solving process is what makes mathematization enduring, for as the mathematician Halmos put it, "if somebody else draws pictures for me, I can't absorb them, I can't see them” (cited in In Touch with God: An Interview with Paul Halmos Albers, 2004, p. 11).

To illustrate the above, one may take the example of innumeracy and financial illiteracy, two issues of relevancy to the general population. Is it a good deal to buy furniture now and pay nothing till 2005 or should one refinance a home because a television ad makes it seem so easy to get extra cash from such an operation? Is an advertised sale really a bargain? Should one save or invest? Answers to such questions require at the very least the ability to calculate and compare mathematical results. Mathematical abstractions applied to rates of return on specific investments, or to the understanding of compounded interests become issues of practical importance in real life financial planning situations. The examples can be extended to more complex situations and broader, social, economic, or political environments. Children who learn to love mathematics will not be handicapped when they are faced as adults with such questions and considerations.

Conceding the importance of mathematics and its practical importance and the resultant need for students to learn and acquire a love for mathematics so that it can be of lasting benefit to them should not however, blind mathematicians to the fact that it took hundreds of years to develop the science of mathematics as it stands today. Consequently, teachers of mathematics cannot expect to force all that knowledge into students in a matter of a few months or years. Time, a special learning environment, and appropriate methodology are needed, and as Piaget has taught us children learn best when they do so at their own pace and through examples that make sense to them, and in a nurturing learning environment. Mathematics teachers can be therefore more efficient in their teaching if they help students develop problem-solving capabilities and enhanced mathematical learning trajectories. Teachers should provide children with the tools to learn how to become lifelong learner, thinkers, and problem solvers. The Freudenthal "flexible framework" method offers an ideal solution to provide a teaching/learning framework for reaching these goals. Does it take time? Yes. Is it time consuming? Yes. Is it worth it? Absolutely.

\section{Learning to Think in a System: A Lesson for Teacher Candidates}

A large percentage of undergraduate teacher candidates come from the traditional school system. Practices in such a system follow the traditional trend of teachers as knower presenting material to students in a manner the teacher sees fit, with little feedback or input from students. Students learn what they have been taught (Schifter \& Fosnot, 1993), prepare for, and take examinations aimed at measuring their retention of taught/learned content. The emphasis is more on retention and recall. Understanding of the systematic constructs that supply meaning to learned mathematical principles is missing from such a teaching-learning paradigm. To facilitate better understanding and induce mathematical thinking, students have to be introduced to a system approach to mathematics, one in which they can see interconnections and apply those in meaningful ways. 
Teacher candidates, whose elementary and high school education was usually of the traditional mold, could find the flexible and systematizing atmosphere of the Freudenthal approach strange. Introducing them to it therefore required encouraging a new way of thinking from the very beginning. The course within which this exercise was first introduced was an interdisciplinary Math, Science and Music methods training course, the first methods course after the required foundation courses for College of Staten Island elementary education students. The author, responsible for teaching the mathematics education segment of the course, elected to use it as platform to introduce this new approach. Teacher candidate arriving at their first mathematics session were challenged to operate and think in a new mathematical system, rather than think, construct and solve within the systems they were familiar with. The challenge was modeled on Simon’s X-Mania system (Schifter \& Fosnot, 1993, p. xv).

\section{X-Mania Challenge: Understanding Mathematical Systems}

The instructor greeted the new class with the following words: "Welcome to CSI. I would like to invite you on a journey. You are in this class by choice; this is your dream class. So please relax. Are you comfortable? Close your eyes. We are leaving this room, this college, New York, the United States, the planet Earth. We are going far away, very far away. Now, you may open you eyes as we arrive at our destination. You are now on a new planet called X-Mania. Very unusual customs abound here. Here the inhabitants do not know numbers, they have never heard about numbers. All they use are letters, which they use to count. For example a single unifix cube $\square$ is counted as A, $\square \square$ becomes B, $\square \square \square \mathrm{C}, \square \square \square \square \mathrm{D}$, $\square \square \square \square \square$ E, $\quad \square \square \square \square \square \square$ A-, $\quad \square \square \square \square \square \square$ AA. What follows this?”

For students to be able to understand what follows, they should understand and stay within the system of X-Mania (see Zolkower 1999). Those who provide an AB answer have started to figure out the system. If they can explain to their classmates why $A B$ follows, then they have understood the system so far. They can proceed from $\mathrm{AA}$ to $\mathrm{AB}$ to $\mathrm{AC}$ to $\mathrm{AD}$ to $\mathrm{AE}$. When they get however to what follows after $\mathrm{AE}$, they will need a greater understanding of the system to know it should be B-. Once they get there, they will have to meet a new challenge at EE. If they can apply their systemic understanding, they can get to A--. Having arrived at this level of complexity, students can begin to explore whether the four basic operations of addition, subtraction, multiplication, and division can be performed in this system. As they explore such questions, they may come to the realization that this number system is a base six system. They may uncover relationships between the base six system and their own familiar base ten system. They may come to see the importance of placeholders, and notice that the '-' performs the same placeholder function as ' 0 ' in the base ten system. And they may finally conclude that much higher levels of operation are possible within the X-Mania system besides the four basic, and discover that other viable systems are possible besides those they are used to, that once operations are conducted with an understanding of their system, they become comprehensible and doable; they become logical. Mathematics, viewed within a system, becomes not only rational but also sensible and learnable. The challenges and lessons of the X-mania exercise remind students that offering students a chance to explore problems and discover the logic behind mathematical constructs facilitates better understanding and ownership of student learning and performance. 


\section{Reaction}

Thurston (1990) summed up the experience of learning and using mathematical knowledge in the following words:

Mathematics is amazingly compressible: you may struggle a long time, step by step, to work through some process of idea from several approaches. However, once you really understand it and have the mental perspective to see it as a whole, there is often tremendous mental compression. You can file it away, recall it quickly and completely when you need it, and use it as just one-step in some other mental process. The insight that goes with this compression is one of the real joys of mathematics. (p. 847)

Student experiences at the College of Staten Island reflected this observation, and the comments of many students validated Thurston's message. As one student put it: "I agonized over mathematics and had initial problems with understanding the Xmania [sic] system, but I worked very hard, now I get pleasure from teaching math.”

A survey of thirty-one ( $\mathrm{n}=31$ ) involved in the X-mania learning experience revealed the problems associated with, as well as the benefits of such a system approach to mathematics education. Though twenty-seven $(87.1 \%)$ encountered difficulties with application in later classrooms with their students, twenty-five (80.6 \%) still conceded its positive influence on how they now teach their students mathematics, and only six (19.3\%) reported predominantly negative experiences with attempts to apply $\mathrm{X}$-mania lessons to the teaching of mathematics. Regarding the last experience five had both negative as well as positive experiences, while that of twenty-six (83.8 \%) was mainly positive.

The experience as a whole happened to have a reformatory influence on the thinking and pedagogy of student teachers. All successfully graduated, and fourteen (45.2\%) were assigned as a master student for this kind of advanced mathematics method course, and seven (22.6\%) decided to do their master's thesis in this field. Three of them presented their research findings at the 2004 National Council of Teachers of Mathematics (NCTM) Conference.

One expressed opinion was, "I no longer look at math as a threat but instead as a challenge. I guess all the years of me struggling actually were a gift. All my students tell me that they understand the math better, because, I help them think in a way that they can comprehend. I handed my request in for next September, I asked to teach math again!” One other student's comments summarized the predominant sentiment: "I think the X-mania experience I had in college was great. It affected my teaching of mathematics in a positive way. Math always seemed like it had to be 'cut and dry.' There was always the correct answer and one way of getting there. Now I look at math differently and try to persuade the children to see it in a different and fun way.”

\section{Conclusion}

To learn a system, to learn to think of mathematics as involving a system, and to do so with experiences that are drawn from the world of the learner and to which the learner can relate on a personal level is the essence of Freudenthal's approach to teaching mathematics. Freudenthal also knew that moving from the conventional approach of horizontal mathematization, in which problem solving moved through defined formulas to inevitable solutions, to a vertical approach that allowed for multiple solutions and learning styles, requires deep understanding. That is why he wrote: "Mathematics starting at, and 
staying within reality, must be understood” (Freudenthal, 1991,p. 18). It is the duty of mathematics teachers to facilitate that understanding, and as the X-mania experience of students of the City University of New York College of Staten Island reported here shows, the effort could be worthwhile.

\section{References}

Albers, D. (2004). In touch with God: An interview with Paul Halmos. The College Mathematics Journal 35(1), 2-14.

Fosnot, C.T. (1996). Preface. In Fosnot, C. T. (Ed.). Constructivism: Theory, perspective, and practice, New York: Teachers College Press, pp. ix-xi.

Fosnot, C.T. \& Dolk, M. (2001). Young mathematicians at work: Constructing number sense, addition, and subtraction. Portsmouth, NH: Heinemann.

Fosnot, C.T. \& Dolk, M. (2001). Young mathematicians at work: Constructing multiplication and division. Portsmouth, NH: Heinemann.

Fosnot, C.T.\& Dolk, M. (2001). Young mathematicians at work: Constructing fractions, decimals, and percents. $\mathrm{x}$ Portsmouth, NH: Heinemann.

Freudenthal, H. (1978). Weeding and sowing. Boston: D. Reidel Publishing Co.

Freudenthal, H.(1991). Revisiting mathematics education: China lectures. Dordrecht (I believe this needs a country; at the very least, it needs a state if it is USA Kluwer Academic Publishers.

Gravemeijer, K. \& Treffers, A. (2000). Hans Freudenthal: a mathematician on didactics and curriculum theory. Journal of Curriculum Studies 32(6), 777-796.

Gravemeijer, K. (1994). Developing realistic mathematics education. Utrecht, The Netherlands Holland: Freudenthal Institute. Numbers 8 and 9 should be in reverse order: when there is a single author and the same author as co-author, the single comes first.

Heuvel-Panhuizen, M. van den. (1996). Assessment and realistic mathematics education, Utrecht, Holland: Freudenthal Institute.

Kerekes, J., \& Fosnot, C. T. (1998). Using pictures with constraints to develop multiplication strategies. The Constructivist 13 (2), 15-20.

O’Connor, J. J., \& Robertson E. F. (2000). Hans Freudenthal school of mathematics and statistics. Scotland: University of St. Andrews.

Schifter, D., \& Fosnot, C. T. (1993). Reconstructing mathematics education: Stories of teachers meeting the challenge of reform. New York: Columbia University Teachers College.

Streefland, L. (1991). Realistic mathematics education in primary school, Utrecht, The Netherlands Holland: Freudenthal Institute. 
Tall, D. (1994). Understanding the process of advanced mathematical thinking. Lecture at the International Congress of Mathematicians, Zurich, Switzerland.

Tall, D. (1993). Mathematicians thinking about Students thinking about Mathematics. Retrieved March 12, 2004, from http://www.warwick.ac.uk/staff/David.Tall/pdfs/dot1993a-lms-newsletter.pdf

Treffers, A. (1987). Three dimensions, a model of goal and theory description in mathematics instruction: The Wiskobas Project, Dordrecht, The Netherlands: Reidel.See above note. I believe this needs a country, and the publisher should be stated the same way in both citations.

Treffers, A. (1991). Realistic mathematics in the Netherlands 1980-1990. In Streefland, L. (Ed.), Realistic mathematics education in primary school (pp.11-20). Utrecht, The Netherlands Holland: Freudenthal Institute., 


\section{Notes}

